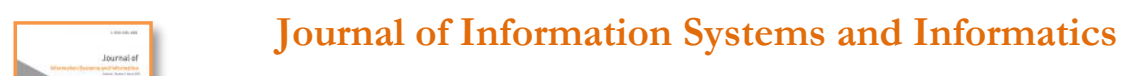

Vol. 2, No. 1, March 2020 e-ISSN: 2656-4882 p-ISSN: 2656-5935

http://journal-isi.org/index.php/isi

Published By DRPM-UBD

\title{
Population Distribution Information System in Tugumulyo District
}

\section{Sistem Informasi Penyebaran Penduduk di Kecamatan Tugumulyo}

\author{
Ahmad Syazili', Ahmad Mutatkin Bakti ${ }^{2}$ \\ 1,2Program Studi Teknik Informatika, Universtias Bina Darma, Palembang, Indonesia \\ Email: ${ }^{1}$ syazili@binadarma.ac.id, 2mutatkin@binadarma.ac.id
}

\begin{abstract}
Information on population data is quite important information for stakeholders. Information on population data is often used in various ways such as aiding, or government activities related to population data. The information that is often needed is related to the actual existence of the population in order to conduct a census or other social interests. For this reason, in this study the development of a population mapping information system in Tugumulyo sub-district was made as an effort to provide information to the public regarding population data. In the process of developing information systems, web engineering development methods are used. Web engineering method is a method used to develop a web-based information system. The results of the development in the form of a population distribution information system with the main features of population data information are presented in the form of tables, graphics and maps. In addition, the information displayed can be seen based on the sub-district and also the village or village in the sub-district.
\end{abstract}

Keywords: Information System, Population, Web Engineering, Tugumulyo District

\section{PENDAHULUAN}

Perkembangan teknologi informasi memberikan dampak pada semua aspek bidang kehidupan dari bidang perdagangan, pemerintahan, sosial, ekonomi, pendidikan bahkan sampai bidang geografi. Dalam bidang geografi, pemanfaatan perkembangan teknologi informasi salah satunya adalah pembuatan peta secara digital atau terkomputerisasi [1]. Peta atau gambaran permukaan bumi sangat berguna untuk mengetahui kenampakan permukaan bumi serta informasi yang terkandung di dalamnya. Dengan peta digital dimungkinkan penampakan permukaan bumi dapat ditampilkan secara jelas dan informasi yang terkandung di dalam peta dapat dilakukan perubahan sesuai dengan perkembangan [2]. 
Sistem informasi geografis dapat digunakan oleh berbagai bidang ilmu, pekerjaan, atau peristiwa seperti arkeologi, agrikultur, keamanan dan pertahanan, kesehatan, pemerintahan, kehutanan, pendidikan, kependudukan, kelautan, hasil alam, bencana, dan tempat wisata [3]. Sistem informasi geografis dapat menjawab pertanyaan-pertanyaan umum dan kompleks yang terjadi dalam suatu instansi, sistem informasi geografi juga dapat membantu dalam pengambilan keputusan yang lebih baik. Sebagai contoh, yang dapat dibuat dengan dasar sistem informasi geografis adalah pemetaan daerah penyebaran penduduk pada suatu wilayah.

Dengan memetakan persebaran penduduk maka akan diketahui daerah yang tergolong padat penduduk, sehingga dapat dijadikan pedoman untuk pengambilan keputusan oleh pemerintah. Tidak terkecuali di wilayah Kecamatan Tugumulyo, untuk mengetahui sebaran penduduknya maka perlu dibuat sebuah pemetaan sebaran penduduk. Pemetaan sebaran penduduk ini sangat berguna untuk mengetahui daerah sebaran penduduk di Kecamatan Tugumulyo, yang nantinya hasil pemetaan ini dapat digunakan untuk mengambil suatu keputusan bagi pemerintah. Akan tetapi pada umumnya pemetaan yang dibuat masih bersifat statis, yaitu informasi yang terkandung di dalam peta tidak dapat dilakukan perubahan sesuai dengan perkembangan atau dengan kata lain peta yang dibuat adalah peta dalam bentuk print out. Oleh karena itu, perlu adanya pengembangan sebuah sistem informasi sebaran penduduk Kecamatan Tugumulyo berbasis web yang dapat memberikan informasi mengenai sebaran penduduk Kecamatan Tugumulyo, serta dapat memberikan informasi kenampakan geografis Kecamatan Tugumulyo secara lengkap dan informasi yang terkandung di dalam peta dapat diperbaharui sesuai dengan perkembangan.

\section{METODOLOGI PENELITIAN}

\subsection{Metode Pengumpulan Data}

Untuk melakuka pengumpulan data maka teknik pengumpulan data yang digunakan yaitu sesuai dengan jenis data. Jenis data tersebut yaitu data sekunder dan primer. Untuk melakukan pengumpulan data primer atau secara langsung dari objek yang diteliti. Adapun cara-cara yang dipakai untuk mengumpulkan data tersebut adalah sebagai berikut:

a. Metode Observasi, Peneliti melakukan pengumpulan data dengan melakukan pengamatan langsung ke Kecamatan Tugumulyo Kabupaten Musirawas sesuai dengan ruang lingkup masalah.

b. Metode Wawancara, Peneliti mengadakan tanya jawab atau wawancara dengan masyarakat dan pihak pemerintah Kabupaten Musirawas khususnya pada Kantor Kecamatan Tugumulyo Kabupaten Musirawas.

c. Metode Dukumentasi, Peneliti mencari data-data yang dibutuhkan dari dokumen-dokumen seperti struktur organisasi yang ada hubungannya 
dengan pembahasan masalah-masalah serta melengkapi data-data yang diperlukan dalam penelitian penelitian laporan penelitian tentang Sistem Informasi Geografis Penyebaran penduduk di Kecamatan Tugumulyo Kabupaten Musirawas menggunakan bahasa pemograman PHP, MySQL dan Google Maps API.

Sedangkan pengumpulan Data Sekunder dilakukan dengan cara mengumpulkan data teoriti, baik dari artikel jurnal, artikel konferensi, buku-buku referensi yang relavan, serta dari hasil penjelajahan (browsing) di internet yang berhubungan dengan penelitian ini.

\subsection{Metode Pengembangan Sistem Informasi}

Metode yang digunakan dalam pengembangan sistem informasi ini adalah model rekayasa web (web engineering), rekayasa web mengadaptasi rekayasa perangkat lunak dalam hal konsep dasar yang menekankan pada aktifitas teknis dan manajemen. Metode ini memerlukan pendekatan yang sistematik dan sekuensial yang mulai pada tingkat dan kemajuan sistem pada setiap tahapan. Pada model ini terdapat aktifitas-aktifitas sebagai berikut:

a. Formulasi, Formulasi dan analisis sistem dan aplikasi berbasis web adalah serangkaian aktifitas rekayasa web yang dimulai dengan identifikasi tujuan dan diakhiri dengan pembangunan analisis model atau spesifikasi requirement sistem. Formulasi memungkinkan klien dan pembangun untuk menetapkan tujuan-tujuanpembangunan web.

b. Analisis Rekayasa Web, Pada tahap ini hal yang akan dilakukan adalah menentukan persyaratan - persyaratan teknik dan mengidentifikasi informasi yang akan ditampilkan pada aplikasi berbasis web. Analisis yang digunakan pada rekayasa web dilakukan dari empat sisi, yaitu : Analisis isi informasi, mengidentifikasi isi yang akan itampilkan pada aplikasi berbasis web ini. Isi informasi dapat berupa teks, grafik, audio, maupun video. Analisis interaksi, analisis yang menunjukkan hubungan antara web dengan pengguna. Analisis fungsional, analisis tentang proses bagaimana aplikasi berbasis web ini akan menampilkan informasi kepada pengguna. Analisis konfigurasi, konfigurasi yang digunakan pada aplikasi berbasis web, internet, intranet, atau extranet. Selain itu, analisis ini juga meliputi relasi database dengan web jika diperlukan.

c. Desain Web, Tahap ini hal yang akan di lakukan adalah menggambarkan struktur WebApp menentukan navigasi halaman-halaman web. Setelah arsitektur WebApp sudah terbentuk dan komponen-komponen seperti halaman, scripts, applet dan fungsi lain sudah ada, maka menentukan navigasi yang memungkinkan user mengakses isi $W e b A p p$ dan layanan-layanannya.

d. Implementasi dan pengujian, Suatu kegiatan untuk mewujudkan desain menjadi suatu web site. Teknologi yang digunakan tergantung dengan kebutuhan yang telah dirumuskan pada tahap analisis. Pengujian dilakukan 
setelah implementasi selesai dilaksanakan. Pengujian meliputi beberapa parameter yang akan menentukan standar aplikasi berbasis web yang telah dibuat. Tahap pengujian adalah suatu proses untuk menguji aplikasi berbasis web yang telah selesai dibuat. Hal ini bertujuan untuk menemukan kesalahan dan kemudian memperbaikinya. Ada beberapa pendekatan yang digunakan untuk melakukan pengujian, yaitu:

1. Pengujian fungsional dan operasional (fungsional and operational testing), Bertujuan untuk menguji masukan dan keluaran dari aplikasi ini.Hasil keluaran aplikasi bergantung dari teknologi yang digunakan, baik itu bahasa pemrograman maupun bahasa skrip yang digunakan.

2. Pengujian navigasi (navigation testing), Hal ini digunakan untukmelihat kesesuaian antara desain navigasi dengan navigasi yang ada di aplikasi. Navigasi berhubungan dengan link-link yang terdapat didalam aplikasi.

3. Pengujian konfigurasi (configuration testing), Pengujian ini dilakukan pada sistem operasi, browser, sistem perangkat keras dan perangkat lunak pendukung. Pengujian ini dilakukan untuk menentukan batas toleransi kebutuhan aplikasi akan perangkat lunak dan perangkat keras pendukungnya.

4. Pengujian keamanan dan performansi (security and performance testing), Pengujian ini dilakukan untuk melihat tingkat keamanan aplikasi dengan cara menguji aspek-aspek yang dapat menimbulkan gangguan keamanan aplikasi maupun server. Keamanan aplikasi sangat bergantung pada teknologi pengembangan website, konfigurasi server yang digunakan dan kelakuan sistem. Pengujian performansi dapat dilakukan bersamaan dengan pengujian keamanan aplikasi, karena keamanan aplikasi berbasis web juga tergantung dari performansi server dan aplikasi tersebut.

e. Evaluasi, Suatu kegiatan akhir dari siklus proses rekayasa web, yang akan menentukan apakah web yang telah selesai dibuat tersebut sesuai dengan yang permintaan. Apabila aplikasi berbasis web ini belum sesuai dengan permintaan, maka proses rekayasa web akan terus dilakukan dan dimulai lagi dari tahap formulasi.

\section{HASIL DAN PEMBAHASAN}

\subsection{Pemodelan Sistem Informasi}

Pemodelan Sistem informasi dibuat menggunakan diagram unified modeling language (UML). Diagram ini merupakan diagram yang digunakan untuk menggambarkan bagaimana sistem informasi sebaran penduduk yang ada di Kecamatan Tugumulyo. Diagram UML juga memiliki berbagai macam diagram diantaranya adalah use case diagram, activity diagram dan sequence diagram. Use case diagram digunakan untuk menggambar bagaimana interaksi antara pengguna dan 
Vol. 2, No. 1, March 2020

p-ISSN: 2656-5935

http://journal-isi.org/index.php/isi

e-ISSN: 2656-4882

sistem informasi yang akan dihasilkan [4]. Untuk itu pada Gambar 1 dapat dilihat merupakan use case diagram sistem informasi sebaran penduduk pada Kecamatan Tugumulyo.

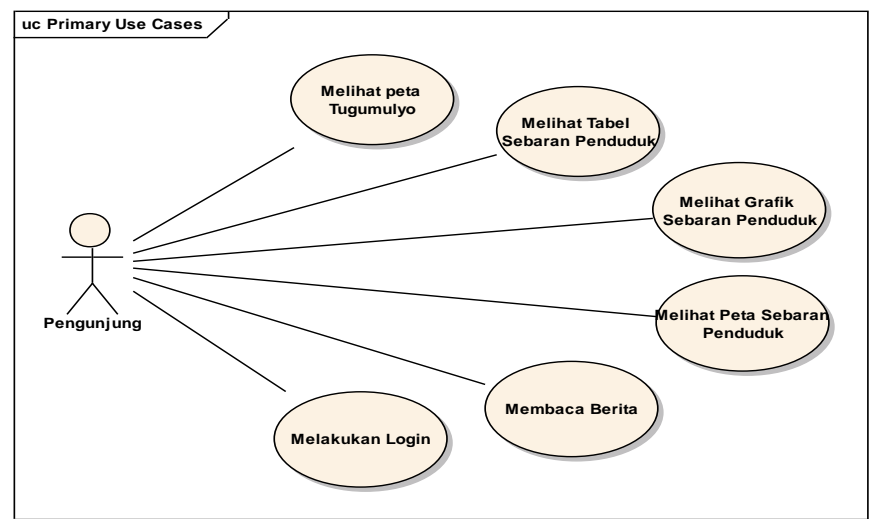

Gambar 1. Use Case Diagram Sistem Informasi

Telihat pada Gambar 1 yang menggambarkan fungsionalitas Sistem Informasi Geografis Pemetaan penduduk di Kecamatan Tugumulyo Kabupaten Musirawas maka peneliti menggunakan use case diagram yang merupakan bagian dari unified modeling language (UML) [5]. Penggunaan UML sendiri dilakukan karena Sistem Informasi Geografis Letak Penduduk di Kecamatan Tugumulyo Kabupaten Musirawas ini akan dikembangkan berbasis web. Selanjutnya adalah untuk melihat bagaimana tingkah laku dari sistem informasi maka digambarkan dalam bentuk activity diagram. Untuk itu pada Gambar 2 dapat dilihat merupakan activity diagram untuk sistem informasi sebaran penduduk pada kecamatan Tugumulyo.

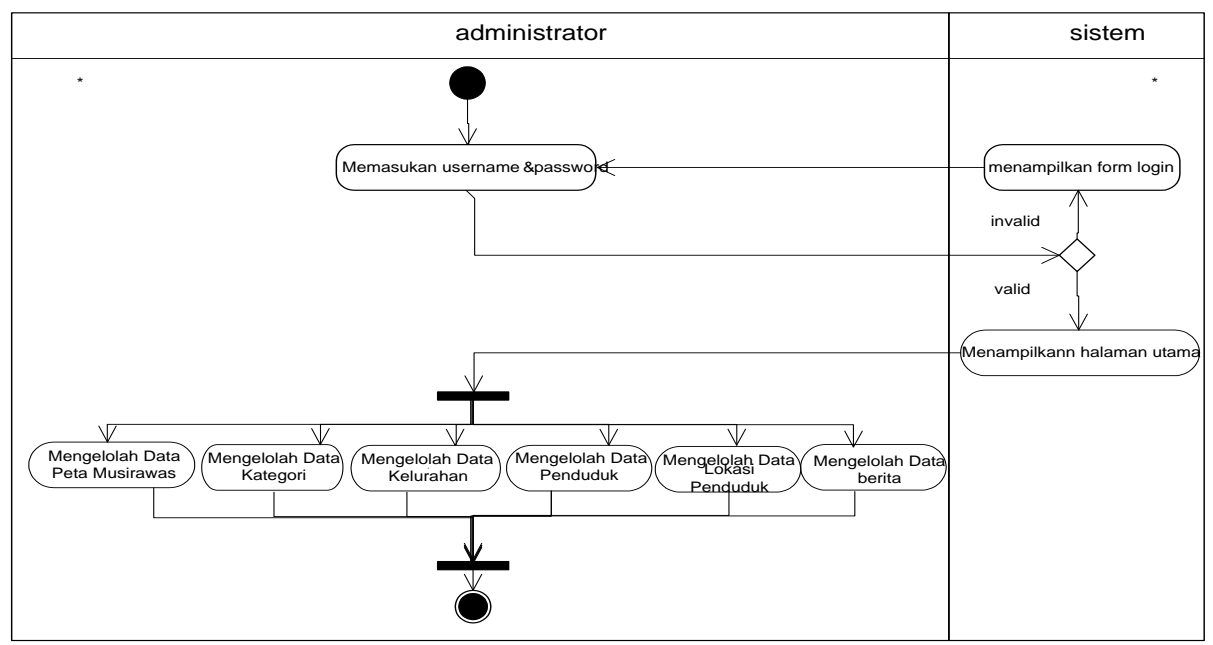

Gambar 2. Activity Diagram Sistem Informasi 
Vol. 2, No. 1, March 2020

p-ISSN: 2656-5935 http://journal-isi.org/index.php/isi

e-ISSN: 2656-4882

Selanjutnya untuk memodelkan jalur kerja, memodelkan aktifitas aktor, bagaimana objek-objek bekerja, aksi-aksi dan pengaruh terhadap objek maka dapat digambarkan melalui sequence diagram [6]. Sequence diagram sistem informasi geografis pemetaan penduduk di wilayah Kecamatan Tugumulyo Kabupaten Musirawas berbasis web terlihat pada Gambar 3. Pada squence diagram yang terlihat pada Gambar 3 adalah sequence yang dilihat dari sisi administrator.

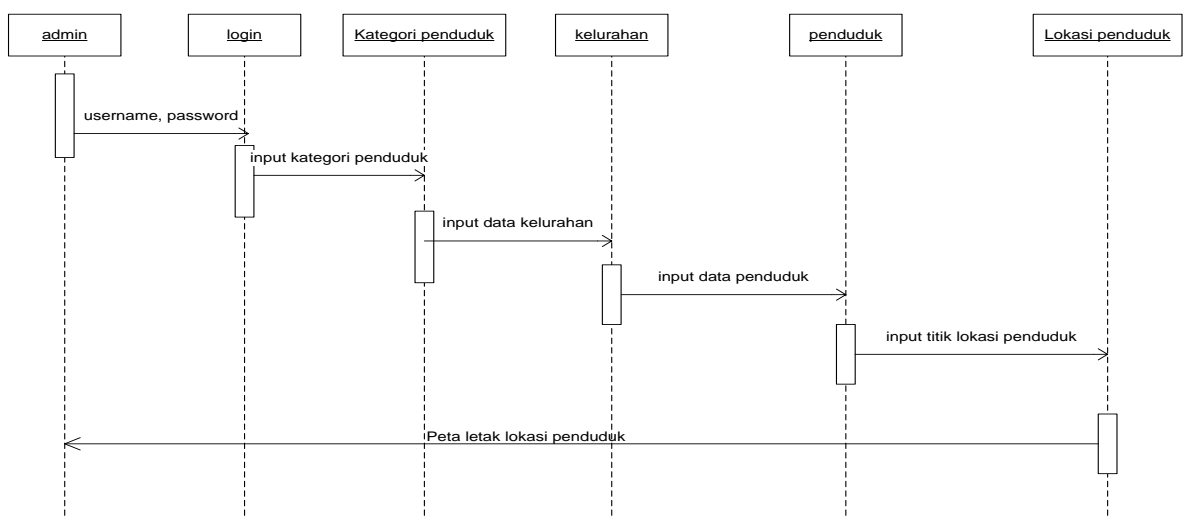

Gambar 3. Sequence Diagram Sistem Informasi

\subsection{Sistem Informasi Sebaran Penduduk}

Setelah proses pemodelan yang dilakukan maka selanjutnya adalah melakukan pengembangan sistem informasi sesuai dengan langkah-langkah metode pengembangan web engineering. Hasil dari proses pengembagnan tersebut berupa sistem informasi sebaran penduduk pada Kecamatan Tugumulyo. Gambar 4 merupakan tampilan halaman utama sistem informasi yang dihasilkan.

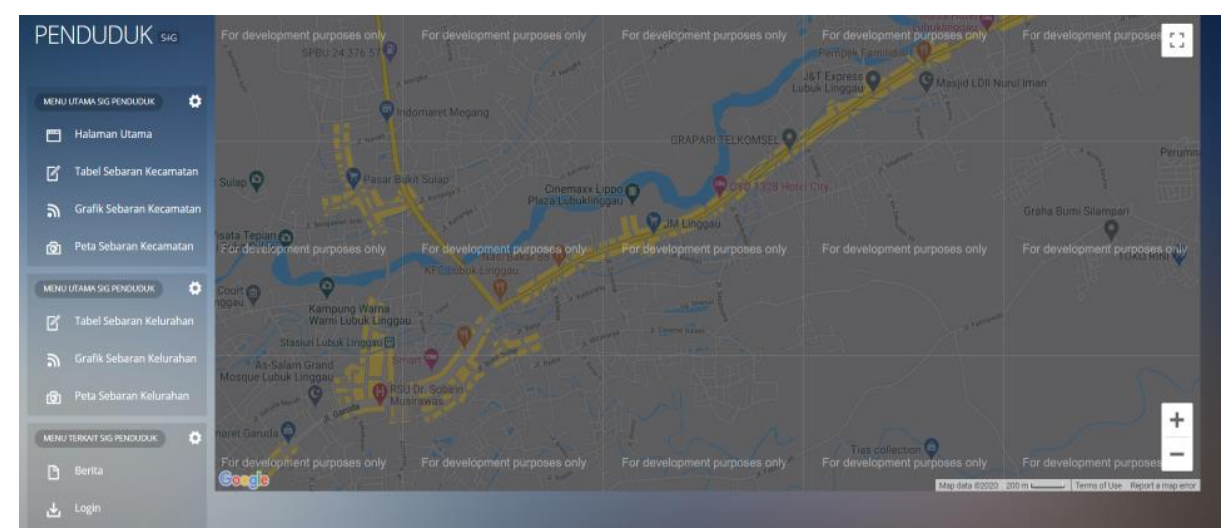

Gambar 4. Tampilan Halaman Utama Sistem Informasi 
Dari Gambar 4 dapat diketahui bawah terdapat berbagai menu yang dapat diakses pengguna dari sistem informasi. diantara menu tersebut adalah tabel sebaran penduduk kecamatan, grafik penduduk kecamatan, dan peta sebaran penduduk kecamatan. Selain itu juga terdapat menu untuk melihat data penduduk untuk masing-masing kelurahan atau desa. Gambar 5 dapat dilihat merupakan informasi penduduk untuk menu tabel penduduk untuk seluruh kecamatan.

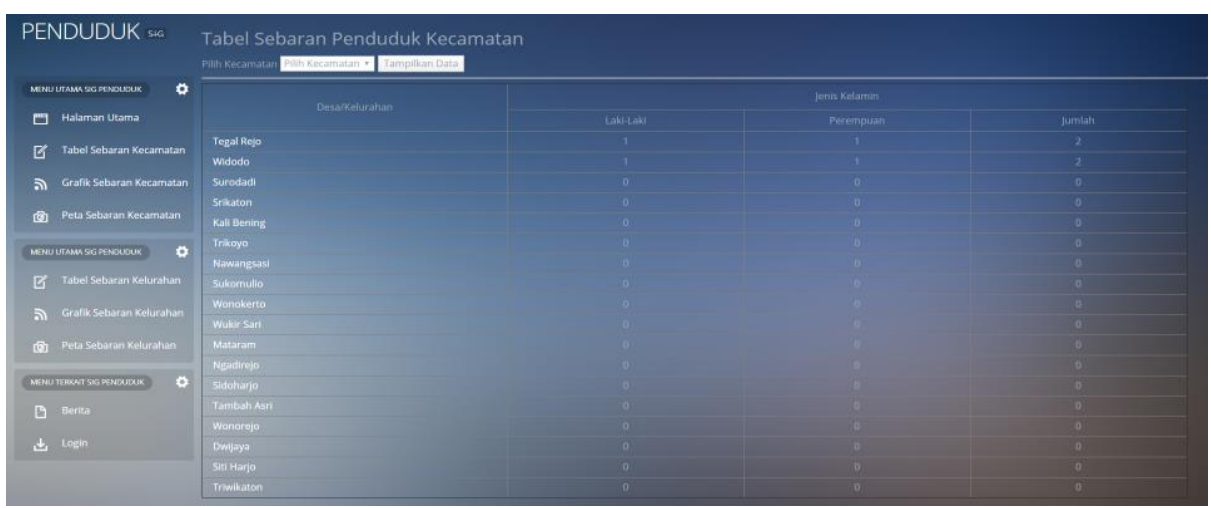

Gambar 5. Tabel Sebaran Penduduk Kecamatan

Selain melihat informasi data penduduk dalam bentuk tabel pengguna juga dapat melihat informasi data penduduk dalam bentuk grapik. Dalam melihat data penduduk dalam bentuk grapik ditampilkan dan dikelompokkan berdasarkan masing-masing kelurahan atau desa penduduk. Selain itu juga informasi data penduduk ditampilkan berdasarkan jenis kelamin penduduk. Grapik data penduduk seperti yang diperlihatkan pada Gambar 6.

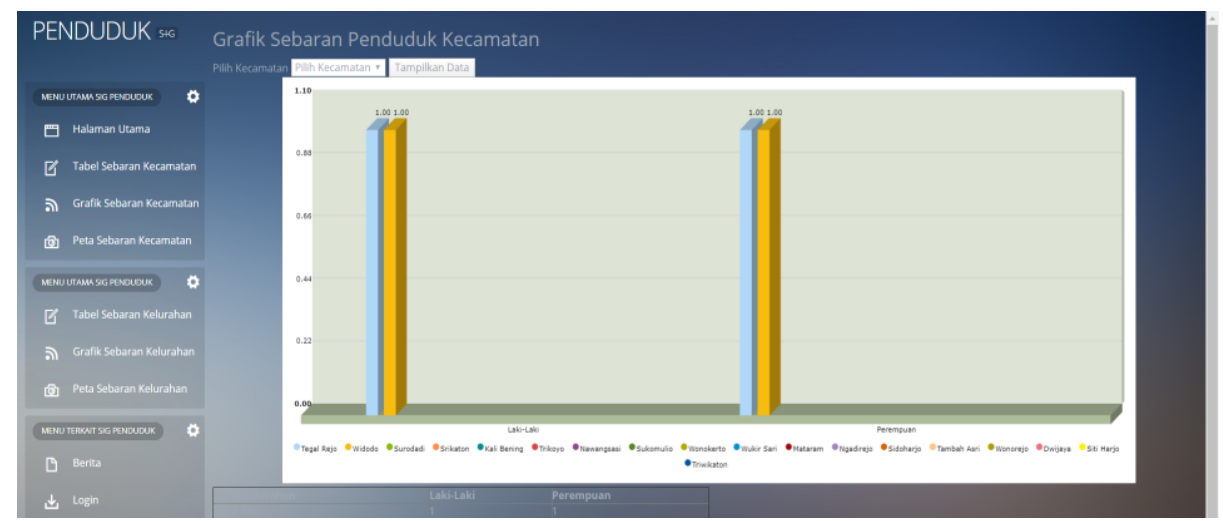

Gambar 6. Grapik Sebaran Penduduk Kecamatan

Untuk melihat sebaran penduduk yang ada pada Kecamatan Tugumulyo maka dapat dilakukan melalui menu peta seabaran kecamatan. Informasi yang 
ditampilkan pada menu ini berisikan informasi keberadaan penduduk sesuai dengan data yang telah dimasukkan pada pengguna administrator. Sealain keberadaan lokasi penduduk dapat juga dilihat detail informasi penduduk seperti yang ditampilkan pada Gambar 7.

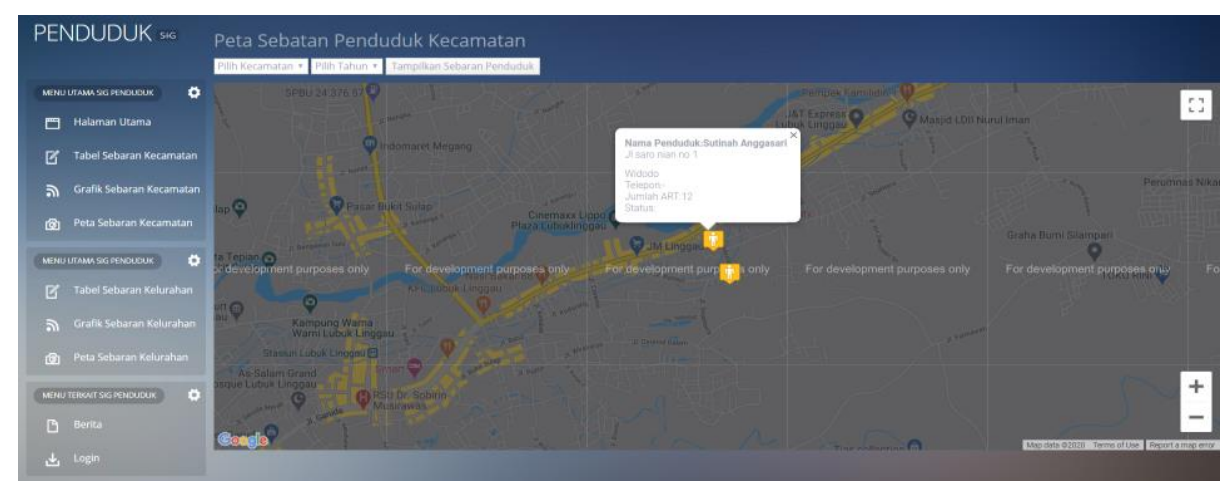

Gambar 7. Peta Sebaran Penduduk Kecamatan

\section{KESIMPULAN}

Sesuai dengan uraian yang telah dikemukakan maka dapat disimpulkan beberapa hal diantaranya adalah (1) sistem informasi yang dihasilkan telah dikembangkan menggunakan metode web engineerin. (2) sistem informasi dilakukan pemodelan agar mendapatkan hasil yang sesuai dengan kebutuhan pengguna. (3) sistem informasi yang dihasilkan memiliki fitur untuk menyajikan informasi baik dalam bentuk tabel, grapik dan peta, sehingga memudahkan pihak terkait dalam mencari informasi data penduduk khususnya pada Kecamatan Tugumulyo.

\section{REFERENSI}

[1] U. Ependi, "GEOGRAPHIC INFORMATION SYSTEM SEBARAN SMA DI KOTA PALEMBANG BERBASIS WEB," in Seminar Nasional Inovasi dan Tren (SNIT) 2014, 2014, pp. 108-113.

[2] F. Syakti, "Sistem Informasi Geografis Penderita Malaria pada Kelurahan Cereme Taba Kota Lubuklinggau," Digit. Zo. J. Teknol. Inf. dan Komun., vol. 10, no. 2, pp. 178188, 2019.

[3] G. W. Sasmito, "Penerapan Metode Waterfall Pada Desain Sistem Informasi Geografis Industri Kabupaten Tegal," J. Inform. J. Pengemb. IT, vol. 2, no. 1, pp. 6-12, 2017.

[4] A. Syazili, F. Fatoni, and R. Sutejo, "Pemodelan dan Implementasi Perangkat Lunak Berbasis Mobile pada Bina Darma TV," JISKA (Jurnal Inform. Sunan Kalijaga), vol. 3, no. 3, pp. 62-69, 2019.

[5] S. D. Purnamasari and F. Panjaitan, "PEMODELAN SISTEM INFORMASI SEBARAN PASAR MENGGUNAKAN UNIFIED MODELING LANGUAGE," JIPI Jurnal Ilm. Penelit. dan Pembelajaran Inform., vol. 4, no. 2, pp. 103-110, 2019.

[6] N. Oktaviani and S. Sauda, "Pemodelan dan Implementasi Aplikasi Mobile Umrah Guide Menggunakan Unified Modeling Language," J. Sains dan Inform., vol. 5, no. 2, pp. 177-186, 2019. 